\title{
Chronic Inflammatory Demyelinating Polyneuropathy
}

\author{
Mazen M. Dimachkie, M.D.* and Richard J. Barohn, M.D. \\ Mazen M. Dimachkie: mdimachkie@kumc.edu \\ *Department of Neurology, University of Kansas Medical Center, 3599 Rainbow Blvd., Mail Stop \\ 2012, Kansas City, KS 66160, USA
}

\section{Opinion statement}

Chronic Inflammatory polyneuropathies are an important group of neuromuscular disorders that present chronically and progress over more than 8 weeks, being referred to as chronic inflammatory demyelinating polyneuropathy (CIDP). Despite tremendous progress in elucidating disease pathogenesis, the exact triggering event remains unknown. Our knowledge regarding diagnosis and management of CIDP and its variants continues to expand, resulting in improved opportunities for identification and treatment. Most clinical neurologists will be involved in the management of patients with these disorders, and should be familiar with available therapies for CIDP. We review the distinctive clinical, laboratory, and electro-diagnostic features that aid in diagnosis. We emphasize the importance of clinical patterns that define treatment responsiveness and the most appropriate therapies in order to improve prognosis.

\section{Keywords}

Chronic inflammatory demyelinating polyneuropathy; CIDP; MADSAM; MMN; DADS; Epidemiology; Clinical manifestation; Nerve conduction studies; Pathogenesis; Treatment; Plasmapheresis; IVIg; Corticosteroids; Prognosis

\section{Introduction}

It is important to recognize CIDP because it represents $21 \%$ of initially undiagnosed neuropathy cases evaluated at the Mayo Clinic and it is responsive to immune system suppression or modulation [1]. In our series from large academic centers in Dallas and San Antonio, CIDP affected $13 \%$ of 402 neuropathy cases referred to our neuromuscular clinic [2]. Academic center data derived from more than 1000 cases in North America (The University of Kansas Medical Center and The University of Texas Southwestern) and 1034 cases from South America (Federal Fluminense University, Brazil) demonstrates a similar proportion of immune-mediated neuropathies ranging from $18 \%$ to $20 \%[3,4]$. Other forms of chronic acquired demyelinating neuropathies are described in Table 1.

(C) Springer Science+Business Media New York 2013

Conflict of interest

Mazen M. Dimachkie declares that he has no conflict of interest.

Richard J. Barohn declares that he has no conflict of interest. 


\section{Epidemiology}

Earlier reported prevalence has ranged from 1 to 7.7 per 100,000, and increased with advancing age with a peak incidence at 40-60 years of age [5-7]. In Olmstead County, the incidence of CIDP was more recently estimated to be 1.6/100,000/year with a prevalence of $8.9 / 100,000$ [5]. The disease can occur at virtually any age with 47.6 years mean age of onset and with a higher prevalence in men than women [6]. Although a relapsing course seems more common between the second and fourth decade; a chronic nonrelapsing course is more common between the fifth and the seventh decade [6].

\section{CIDP}

\section{Clinical features}

CIDP patients typically present with chronic progressive, stepwise progressive or relapsing weakness $[1-3,8]$. The overwhelming majority of patients over the age of 65 have a chronic progressive course for two or more months [1]. Weakness is typically symmetric and characteristically involves proximal and distal muscles [9], occasionally affecting face or neck flexor muscles, and typically sparing of extraocular muscles. Except in pure motor presentation, which affects up to $10 \%$ of cases [10], sensory symptoms include numbness, tingling, gait imbalance, and at times painful parasthesias [10-12]. The sensory variant affects $35 \%$ of cases while classic sensorimotor presentation occurs in $51 \%$ [10]. While muscle stretch reflexes are depressed or absent, autonomic and respiratory insufficiency are uncommon.

The $18 \%$ of CIDP patients who present with the relapsing form are difficult to distinguish from GBS $[10,13,14]$. CIDP cases were more likely than GBS to demonstrate prominent sensory signs and less likely to have autonomic involvement, facial weakness, a preceding infectious illness, or need mechanical for ventilation [13]. The first treatment-related fluctuation (TRF) in GBS always occurred within 8 weeks from onset of weakness and none experienced more than two TRFs [14]. Acute CIDP patients were more likely to maintain independent ambulation, normal cranial nerves, and to display marked demyelination on nerve conduction studies.

Another temporal variant group labeled subacute inflammatory demyelinating polyneuropathy (SIDP) consists of patients who progress for longer than weeks but less than 8 weeks, and therefore do not fall neatly into either the acute or chronic acquired demyelinating neuropathy groups [15-17]. An antecedent infection is found in $38 \%$ of cases with cranial nerve deficits and respiratory failure being rare. CSF protein is elevated in $93 \%$ of cases and demyelination is documented on motor nerve conduction in $88 \%$ of cases. Up to $17 \%$ of cases classified as probable SIDP will relapse when immunosuppressive therapy is discontinued, and these patients ultimately are diagnosed with CIDP. The bottom line is a tincture of time will help distinguish those with future attacks indicative of relapsing CIDP from those with SIDP.

In addition to classic CIDP, other phenotypes sharing some clinical and pathologic features, laboratory findings, and in most cases response to immunomodulatory therapies have been 
described the rubric of chronic acquired demyelinating polyneuropathies (CADP) (Table 1) $[18,19]$. The four categories of CADP are largely based on the phenotypic differences. Symmetrical proximal and distal weakness with or without sensory loss is highly suggestive of CIDP. The pattern of symmetrical distal weakness and sensory loss should raise suspicion of distal acquired demyelinating symmetric (DADS) neuropathy [20]. When weakness is asymmetric, further classification hinges around the presence or absence of sensory signs. Asymmetric distal weakness without sensory loss is indicative of multifocal motor neuropathy (MMN) whereas sensory loss would suggest multifocal acquired demyelinating sensory and motor (MADSAM) neuropathy (Lewis-Sumner syndrome) [21-24]. Up to half of the MMN patients also have serum GM-1 antibodies and most DADS patients have an IgM monoclonal protein in the serum, often accompanied by antibodies to myelin-associated glycoprotein (MAG). Multifocal acquired demyelinating sensory and motor (MADSAM) neuropathy patients have a chronic sensorimotor mononeuropathy multiplex with typically an insidious onset and slow progression. Initial involvement is usually in the arms, with later spread to distal legs. Unlike MMN, MADSAM neuropathy is not associated with anti-GM1 antibodies [21, 25-27]. As in MMN and CIDP, nerve conduction studies in MADSAM neuropathy shows conduction block, temporal dispersion, prolonged distal latencies, slow conduction velocities, and delayed or absent F-waves in one or more motor nerves. In contrast to MMN, sensory NCS are also abnormal at the outset. Though prospective randomized controlled studies have not been performed, retrospective series have demonstrated improvement in response to IVIg in treatment more than $70 \%$ of MADSAM neuropathy patients [21, 25-30]. In contrast to MMN, most patients with MADSAM neuropathy have also shown response to corticosteroid treatment. Therefore it is important to distinguish MADSAM neuropathy from MMN since the former is steroid-responsive while the latter is not.

Preceding viral infections are less common in CIDP compared with GBS. In 2007, a cluster of patients experiencing a polyradiculoneuropathy mimicking CIDP was identified in a swine abattoir table primarily processing severed heads [7]. Workers removed brains by using compressed air that liquefied brain and generated aerosolized droplets, exposing themselves and nearby workers to porcine neural antigens. An immune-mediated pathophysiology was supported by increased levels of interferon-gamma expression.

\section{Laboratory features}

The most important laboratory studies that support of the diagnosis of CIDP are the cerebrospinal fluid (CSF) examination, NCS, and nerve biopsy. Of these three, the CSF evaluation is the most sensitive as protein is elevated in up to $94 \%$ of cases with normal white cells [31, 32]. A CSF white blood cell count exceeding 10/mm3 should lead to suspicion for HIV infection, Lyme disease, sarcoidosis, and lymphomatous, or leukemic nerve root infiltration. Oligoclonal bands are identified in the CSF up to $65 \%$ of CIDP patients [33]. If a paraprotein is detected on serum immunofixation or serum kappa lambda free light chain ratio, a search for a lymphoproliferative disorder, such as osteosclerotic myeloma or lymphoma, should be initiated. Magnetic resonance imaging (MRI) demonstrates an enlargement on $\mathrm{T} 2$ sequences of the spinal nerve roots and contrast enhancement. 
Nerve conduction studies-Nerve conduction studies demonstrate demyelination including slowed motor nerve conduction velocities, prolonged distal motor latencies, delayed $\mathrm{F}$ wave latencies (Table 2), and partial motor conduction block (at least $30 \%$ to 50 $\%$ reduction in proximal amplitude) or abnormal temporal dispersion (prolongation of proximal motor response duration by $30 \%$ or more). Though highly specific to CIDP [34], the AAN research criteria have suboptimal sensitivity of 39\%-43\% as they require abnormalities in three of the above four parameters, with the first three measures affecting two or more nerves [35,36]. We compared several published criteria and found all had similar sensitivities ranging from $52 \%$ to $76 \%$ [37]. More recently, derivation and validation of diagnostic criteria for chronic inflammatory demyelinating polyneuropathy simplified the electrodiagnostic criteria, in cases of progressive neuropathy for more than 8 weeks without monoclonal protein or genetic neuropathy, to more than one-half of studied nerves demonstrating abnormality in either distal latency, conduction velocity or $\mathrm{F}$ wave latency as in Table 2 [38••]. This rule, which applies when $75 \%$ or more of the studied nerves have recordable potentials, had $83 \%$ sensitivity and $97 \%$ specificity in a validation cohort and performed better than published criteria. The EFNS 2010 criteria added prolonged distal CMAP duration from onset of first negative peak to return to baseline of last negative peak in one nerve with one or more other demyelinating parameter in another nerve as supportive of definite CIDP(median $\geq 6.6 \mathrm{~ms}$, ulnar $\searrow 6.7 \mathrm{~ms}$, peroneal $\geq 7.6 \mathrm{~ms}$ and tibial $28.8 \mathrm{~ms}$ ) [39].

Though the 2010 EFNS guidelines recommend a normal sural with abnormal median or radial SNAP pattern as a supportive good practice point [39], there is controversy around the utility of sensory nerve conduction studies in supporting the diagnosis of CIDP. We retrospectively compared 52 CIDP cases with 35 cryptogenic sensory neuropathy cases and found a lower frequency of sural nerve sparing (8\%) in CIDP with poor specificity [37]. Sensory conduction velocity $<80 \%$ of lower limit of normal ( $<70 \%$ if SNAP amplitude $<80$ $\%$ of lower limit of normal) is also supportive of CIDP according to the 2010 EFNS revision. However, Rajabally and Samarasekera found that SNAP conduction velocities were significantly slower for median and sural nerves in 19 CIDP patients, but ROC curves did not demonstrate cut-offs with useful sensitivities/specificities when compared with control cases with distal large fiber sensory axonal neuropathy [40]. The 2010 EFNS guidelines also suggest that somatosensory evoked potentials can support the diagnosis of CIDP by demonstrating abnormal proximal sensory conduction, particularly in sensory CIDP cases with normal sensory nerve action potentials and without central nervous system disease.

An important limitation is that almost all of the proposed criteria focus on NCS, and meeting NCS criteria is a necessary component for most. The derivation and validation study included symmetrical onset of motor symptoms, symmetrical weakness of four limbs, and proximal weakness in one or more limbs as a separate criterion for definite CIDP besides the above noted electrophysiologic criteria [38・•]. Out of 48 CIDP consensus patients in the validation sample, $63 \%$ satisfied the electrophysiologic and clinical criteria, $20 \%$ only the clinical criteria, and $18 \%$ only the electrophysiologic criteria. Most of the patients who met 
only the clinical criteria for CIDP had a prolonged course and secondary axonal loss electrophysiologically.

\section{Histology}

Of the three main laboratory studies, sural nerve biopsy is probably the least useful [41, 42]. Sensory nerve pathology demonstrates foci of endoneurial or perivascular inflammation in only $11 \%$ of 60 cases [32]. The presence of macrophages clusters, namely three or more macrophages, around endoneurial vessels in sural nerve biopsies may serve as a useful additional marker for establishing the pathologic diagnosis of CIDP [43]. Pathologic evidence of demyelination and remyelination is present on teased nerve fiber analysis in only $48 \%$ to $68 \%$ of CIDP cases and up to $21 \%$ had mixed demyelinating and axonal changes [32]. There was considerable overlap in features of demyelination, axonal degeneration, and inflammation in $21 \mathrm{CIDP}$ and 13 chronic idiopathic axonal polyneuropathy patients [42]. As indicated by the 2009 AAN practice parameter, nerve biopsy is of limited diagnostic value in CIDP but may be useful to exclude in atypical CIDP cases mimics such as amyloidosis, vasculitis, sarcoidosis, and lymphomatous infiltration [44].

\section{Pathophysiology}

CIDP is a complex autoimmune disease with evidence in support of both cellular and humoral autoimmunity to an unknown antigen. The main cellular components of inflammatory peripheral nerve infiltrates are epineurial and endoneurial $\mathrm{T}$ cells and macrophages with macrophage-mediated myelin stripping [45]. Myelin sheets may at times be surrounded by macrophages invading the basement membrane and actively stripping myelin lamellae [46]. The $\mathrm{T}$ cells express increased activation markers and inflammatory chemokine receptors, especially CXCR-3 [47], and secrete matrix metalloproteinase 2 and 9 [48]. In support of humoral immune factors, passive sera, and immunoglobulin $\mathrm{G}$ antibodies transfer from patients with CIDP induce peripheral demyelination in recipient animals [49]. Although plasma exchange supports the role humoral factors, autoantibodies to components of peripheral nerve myelin or to neuronal antigens have been inconsistently found in CIDP sera. Antibody-mediated complement attack against peripheral nerve myelin, with resultant myelin stripping and phagocytosis, is supported by the increase in serum levels of complement terminal attack complex [50] and expression of in C3d products on peripheral myelin sheaths [51]. The strongest evidence incriminates $\mathrm{P} 0$, to which antibodies have been found in only $20 \%$ of CIDP cases [52].

CIDP is caused by loss of regulation of immune reaction in response to unknown antigens. Suppressor cell function is defective in CIDP but can be enhanced in vivo by prednisone and plasma exchange in conjunction with clinical improvement [53]. The percentage of circulating regulatory $\mathrm{T}$ cells is reduced in CIDP compared with normal controls [54]. The inhibitory Fc-gamma receptor $(\mathrm{Fc} \gamma \mathrm{R})$ IIB, expressed on myeloid and B cells, plays a critical role in the balance of tolerance and auto-immunity in various murine disease models [55]. Treatment-naive active CIDP patients showed a lower expression of Fc $\gamma$ IIB levels on B cells. Furthermore, CIDP and systemic lupus erythematosus patients share an increased representation of a polymorphism in the promoter for the gene that controls expression of 
Fc $\gamma$ receptor IIB [56]. CIDP cells displayed lower Fas function, a death receptor on activated lymphocytes involved in switching-off the immune response, than both AIDP patients and controls [57]. Fas function was lower in CIDP patients with progressive course or axonal damage than in those with relapsing-remitting course or pure demyelination respectively.

CIDP with concurrent illness-CIDP can occur in the setting of a number of systemic disorders [58-64]. This group has been termed "CIDP with concurrent illness" [32, 65], although the exact relationship of the underlying illness to the development of CIDP differs from case to case. For example, in Charcot-Marie-Tooth disease, the underlying systemic disorder might increase susceptibility to the development of an acquired demyelinating polyneuropathy resulting in acute or subacute deterioration following a long asymptomatic or stable course [66]. In other cases, such as hepatitis $\mathrm{C}$, the concurrent illness may be part of a systemic dysimmune process, polyneuropathy being one of its manifestations. Therefore, these patients should probably be treated no differently from those with idiopathic CIDP.

An Olmsted County epidemiologic study showed that diabetes mellitus occurred no more frequently in CIDP when compared with normal controls [5]. There are patients with diabetes that develop the classic phenotype of CIDP and most respond with stable and prolonged remissions over several years to IVIg administration [67]. In another report, most diabetic CIDP patients fulfilling the AAN criteria improved in the clinical disability grade at 6 months in response to prednisone therapy but to a lesser extent than nondiabetic CIDP cases [68]. TNF- $a$ antagonists administered for various autoimmune diseases have been reported in association with a variety of immune-mediated neuropathies including GBS, MFS, CIDP, MMN and mononeuropathy multiplex [69]. We [70] and others reported cases of tacrolimus-associated CIDP [71-73].

Ten to $20 \%$ of CIDP cases may have a monoclonal gammopathy of undetermined significance (MGUS) $[20,32,74]$. The level of the monoclonal protein is typically reduced and can be missed with serum protein electrophoresis without serum immunofixation [75, 76]. Though most CIDP-MGUS cases generally do not have an underlying lymphoma, osteosclerotic myeoloma, or other lymphoproliferative disorder, they should have radiographic skeletal survey, undergo a hematologic evaluation and in some cases a bone marrow biopsy. Those that have an IgG- or IgA-MGUS frequently respond to immunomodulatory therapy. Patients with an IgM-MGUS usually, but not invariably, have exclusively distal involvement of DADS neuropathy and are less responsive to therapy [20]. Osteosclerotic myeloma can be associated with other system manifestations in the POEMS syndrome of polyneuropathy, organomegaly, endocrinopathy, M-protein, and skin changes. The pathogenesis is related to vasoactive endothelial growth factor (VEGF) production, which can be used as a diagnostic marker [77, 78]. Patients with monoclonal gammopathy, osteosclerotic myeloma, and demyelinating neuropathy should undergo evaluation by skeletal survey, which is more sensitive than nuclear bone scan to detect osteoslerotic lesions [76]. 


\section{Treatment}

Randomized controlled trials have confirmed the efficacy of corticosteroids (CS) [79], plasma exchange [80, 81], and intravenous immunoglobulin (IVIg) [82-84] for the treatment of CIDP. Each of these is an acceptable first-line therapy, although the need for specialized facilities for providing out-patient plasma exchange and prolonged intravenous access makes plasma exchange less appealing. Due to the long-term side effect profile of corticosteroids, there is a trend towards using IVIg as the initial therapy for CIDP. A multicenter, randomized, double-blind, crossover trial compared a 6-week course of oral prednisolone tapering from $60 \mathrm{mg}$ to $10 \mathrm{mg}$ daily with IVIg $2.0 \mathrm{~g} / \mathrm{kg}$ given over 1 to 2 days for treating CIDP [85]. Twenty-four of the 32 randomized patients completed both treatment periods. Though treatment with IVIg did bring about more rapid improvement, there was little difference between the two therapies.

Prednisone therapy is initiated with $100 \mathrm{mg}$ orally once daily in the morning. When improvement begins, usually within 2 to 4 weeks, patients can be switched to alternate day therapy. When strength has returned to normal or improvement has plateaued, usually within three-six months, prednisone dose is slowly tapered by $5 \mathrm{mg}$ every 2 to 3 weeks. Although a minority of patients can eventually be tapered completely off of prednisone, many patients relapse. It is important for both the patient and physician to realize CIDP is a chronic disorder and may require immunosuppressive therapy for one or more years. Some patients will require a steroid-sparing agent to facilitate a downward prednisone taper (see below).

Because the risks of long-term CS therapy are numerous, discussing those with the patient as well as establishing a monitoring plan in collaboration with the primary care physician is integral to the management plan. Before CS initiation we place a PPD skin test to identify the need for isoniazid in previously exposed cases. As we start CS, we obtain a baseline bone DEXA scan and request the patient to seek an ophthalmologic examination, with yearly follow-up for both. We maintain patients on oral calcium 500 to $600 \mathrm{mg}$ two to three times daily with vitamin D 400-800 IU daily. If there is osteopenia or osteoporosis, or there are fractures, we recommend starting an antiresorptive agent such as alendronate. If patients develop gastric irritation, we instruct them to use H2-blockers or proton pump inhibitors. We ask patients and their family to be alert about personality changes and psychiatric side effects. We inform our patients to reduce the salt and carbohydrate in their diet and visit regularly with the primary care physician for blood pressure, serum glucose, and potassium and measurements. We advocate the pneumococcal vaccine and yearly flu shots but caution against live vaccines.

A recent retrospective chart review from the Washington University neuromuscular group suggests that intravenous high-dose methylprednisolone may be an effective treatment for CIDP [86]. To further investigate the potential to reduce CS side effects, an open-label prospective study of pulse oral weekly methylprednisolone was recently conducted [87]. Steroid-induced osteoporosis was however noted in five/nine cases.

The study by Mendell and colleagues established that intravenous immunoglobulin (IVIg) improves strength and functional score more than placebo in newly diagnosed CIDP patients who had not received any other forms of immunosuppressive therapy [83]. The 
pharmacodynamic effects of IVIg in CIDP are rapid with onset of isokinetic muscle strength improvement on day 5 after of IVIg reinitiation and peaking by day 10 in association with gait velocity and hand function response [88]. The INCAT group reported that both IVIg and prednisolone were essentially equally effective when compared in a head-to-head trial [85]. The recently published ICE trial [84] was a randomized, double-blind, placebocontrolled, response-conditional crossover trial included 117 patients with CIDP. Caprylatechromatography purified $10 \%$ immune globulin intravenous or placebo was given every 3 weeks for up to 24 weeks in an initial treatment period. Fifty-four percent of patients treated with IVIg had an improvement in the adjusted INCAT disability score through week 24 compared with $21 \%$ of subjects who received placebo $(P=0.0002)$. Improvements were also recorded for grip strength and in CMAP amplitudes of proximal and most severely affected nerves [89]. During the 24-week extension phase, participants who continued to receive IVIg had a longer time to relapse than did patients treated with placebo $(P=0.011)$. This study led to the first FDA-approved therapy in CIDP.

We recommend an IVIg induction dose of $2 \mathrm{gm} / \mathrm{kg}$ over 2 to 5 days, followed by monthly maintenance doses of $0.4 \mathrm{gm} / \mathrm{kg}$. Based on the ICE study, the suggested maintenance dose may be as high as 1 gram per kilogram every 3 weeks. The range of maintenance dose of 0.2 gram per kilogram weekly to 1.0 gram per kilogram every 3 to 4 weeks with adjustments made on an individual basis. We usually plan to treat patients for 6 months, and then reevaluate to determine if further therapy is needed. We treat with repeated courses for to months before concluding lack of efficacy. While we generally infuse IVIg no faster than 150 to $200 \mathrm{cc} / \mathrm{h}$, a recent report described infusion rates of up to $800 \mathrm{cc} / \mathrm{h}$ in 50 patients, which was reasonably well tolerated [83]. Lee and colleagues treated two CIDP patients with subcutaneous infusion of immunoglobulins (SCIg) after IVIg therapy was shown to be effective. Application of SCIg was well tolerated and led to stabilization of the disease course [90].

Intravenous immunoglobulin (IVIG), a pooled gammaglobulin product from several thousand blood donors, has a complex immunomodulatory mechanism of action. It is thought to involve pathogenic autoantibodies production modulation and binding inhibition, pro-inflammatory cytokine suppression, $\mathrm{Fc}$ receptor blockade, macrophage colony stimulating factor and monocyte chemotactant protein-1 increase, alteration in $\mathrm{T}$ cell function, decreased in circulating CD54 lymphocytes, and inhibition of cell transmigration into the muscle. More recently, investigators from the Rockefeller found that Fc core polysaccharide 2,6-sialylation mediates the anti-inflammatory properties the IVIg [91].

Plasma exchange (PE) was demonstrated to be more effective than "sham" pheresis for CIDP in two important studies with up to $80 \%$ response rate [80, 81]. PE is typically used if patients are severely weak, if they relapse on prednisone or IVIg, or they are unresponsive to these therapies. However, IVIg may also be effective in severely weak patients. Risks of PE include those of central venous indwelling catheter, hypotension, allergic reaction to albumin, hypocalcemia, anemia, thrombocytopenia, and citrate toxicity. The response obtained with plasma exchange is faster than that from prednisone or IVIg. Five to ten treatments are usually performed over 2 to 4 weeks at the initiation of therapy. Unlike the situation in GBS, there is no benchmark goal of how much total fluid to remove. The effects 
of plasma exchange are transient, usually lasting 4 to 8 weeks, but sometimes only 1 to 2 weeks. Therefore, unless another immunomodulatory treatment such as prednisone is given, PE will need to be performed indefinitely, something not typically pursued because of cost, risk to the patient, and often the need for a long-term indwelling vascular access device.

When a patient does not respond to or cannot tolerate the first-line agents, other medications may prove beneficial. Azathioprine, cyclophosphamide, cyclosporine, interferon-alpha, interferon-beta, mycophenolate mofetil, and methotrexate have all been reported to be beneficial in CIDP patients not responsive to initial therapies [92-108]. For the most part, these studies were not prospective, randomized, or blinded. In a small controlled trial, patients randomly assigned to azathioprine $2 \mathrm{mg} / \mathrm{kg}$ and prednisone did no better than those assigned to glucocorticoids alone [92]. Besides azathioprine, mycophenolate mofetil, cyclosporine, and methotrexate are often used as steroid sparing agents. A negative randomized controlled trial of oral methotrexate $15 \mathrm{mg}$ weekly was reported in CIDP [109]. A recent studied evaluating the effects of intramuscular interferon-beta-1a (Avonex) at low (30 micrograms weekly), intermediate (30 micrograms twice weekly or 60 micrograms weekly) and high dose (60 micrograms twice weekly) on IVIg dose in CIDP did not show a significant benefit [104, 105, 110]. High dose cyclophosphamide without stem cell rescue can lead to long-term remission with refractory CIDP [97] with improved quality of life [112]. In progressive demyelinating neuropathy patients with IgM monoclonal gammopathy of unknown significance, oral treatment with fludarabine was well-tolerated and induced stabilization and improvement in modified Rankin scale at 1one year follow-up in 5/16 patients [111].

Targeted therapies have yet to be fully studied in CIDP. Rituximab is a chimeric monoclonal antibody that specifically binds to CD20 antigen, expressed from pre-B-cell stage to mature B-cell stage, on normal and malignant B-lymphocytes. In a retrospective observational study of rituximab in 13 Italian CIDP patients eight of whom had hematologic malignancy $(n=4)$ or MGUS ( $n=4)$, most cases improved with seven/nine responders having an associated hematologic disorder [113]. Response began after a median of 2.0 months (range 1-6) and lasted for a median period of one year (range 1-5). Effects of antibodies directed against CD52 on circulating $\mathrm{T}$ lymphocytes and monocytes following infusion are rapid, with a single dose of alemtuzumab causing depletion of CD8+ T cells for 30 months and CD4+ T cells for 60 months on average. Alemtuzumab was administered in seven severe IVIGdependent CIDP cases refractory to conventional immunosuppression [114]. Mean monthly IVIG use fell by $26 \%$; two patients had prolonged remission, two patients had a partial response, and no clear benefit was observed in the remaining three patients. However, three patients developed autoimmune disease following alemtuzumab treatment.

Radiation and surgical removal of the plasmacytoma is an effective treatment regimen of osteosclerotic myeloma and neuropathy [115]. Omaya and colleagues published the first case report of successful nonmyeloablative autologous stem cell transplant in refractory CIDP [116]. Autologous peripheral blood stem cell transplantation improved refractory CIDP and POEMS syndrome cases with additional normalization of serum VEGF levels $[117,118]$. Thalidomide treatment may be a treatment option for POEMS cases in whom stem cell transplantation is not indicated. In nine POEMS syndrome cases treated with 
thalidomide, all had treatment-induced reduction in serum VEGF levels and six substantially improved in their peripheral neuropathy while three clinically stabilized [119].

In comparison with the 2006 EFNS/PNS joint task force report [120], the 2010 treatment recommendation upgrades the use of IVIg in CIDP to a Level A recommendation, while downgrading corticosteroids therapy in sensory and motor CIDP to Level $\mathrm{C}$ and retaining the Level A recommendation for PE when IVIg and corticosteroids are ineffective [39]. Good practice points include IVIg as the initial treatment in pure motor CIDP as well as combination therapy or adding an immunosuppressant drug if the therapeutic response is inadequate or the maintenance dose of the initial treatment are high. This is in addition to symptomatic treatment and multidisciplinary management.

\section{Prognosis}

In one retrospective series, greater than $90 \%$ of patients with CIDP initially improved with immunosuppressive treatment; however, the relapse rate was approximately $50 \%$ [32]. Only $30 \%$ of patients in this series achieved a complete remission off medication. Two of the patients (3\%) died. It appears the longer patients are followed, the more likely they will relapse [32]. In the Mayo Clinic series, $60 \%$ of patients were improved and able to return to work, another $4 \%$ were in remission, $8 \%$ were ambulatory but unable to work, $11 \%$ were bedridden or wheelchair bound, and six (11)\% died of the disease while three $(6 \%)$ died from other diseases [31]. The 2007 GBS/CIDP Outcomes Survey indicated that over the last three decades the care of CIDP has improved the overall outcome. The mortality rate has decreased to $1.3 \%$ and patients are less likely to be confined to a wheelchair (7\%). The proportion of patients who recovered or are independent while on treatment has increased remarkably to $31 \%$. Despite these improvements due to immunotherapy, the majority of cases remain to have some degree of disability with $28 \%$ requiring an assistive device to ambulate (Koski L, 2007 CIDP Outcomes Survey, personal communication).

Several, more recent prospective studies may provide more reliable numbers regarding how often patients respond to treatment. In controlled trials of IVIg in CIDP patients, $63 \%$ to 76 $\%$ of patients responded $[82,83]$. Symptoms present for less than one year, and an acute relapse at time of IVIg treatment predicted a beneficial response to therapy [82]. Progressive course, CNS involvement (as in $5 \%$ of cases), high proportion of fibers showing active demyelination on nerve biopsy, and axonal loss overall correlated with higher disability. Early and aggressive therapy may prevent secondary axon loss and improve prognosis [121].

\section{References and Recommended Reading}

Papers of particular interest, published recently, have been highlighted as:

•• Of major importance

1. Dyck PJ, Oviatt KF, Lambert EH. Intensive evaluation of referred unclassified neuropathies yields improved diagnosis. Ann Neurol. 1981; 10(3):222-6. [PubMed: 7294727]

2. Barohn RJ. Approach to peripheral neuropathy and neuronopathy. Semin Neurol. 1998; 18(1):7-18. [PubMed: 9562663]

3. Khan S, Wolfe G, Nascimento O, Pasnoor M, et al. North American and South America (NA-SA) Neuropathy project (abstract). Neurology. 2006; 66:A84.

Curr Treat Options Neurol. Author manuscript; available in PMC 2014 June 01. 
4. Pasnoor M, Nascimento O, Trivedi J, Wolfe GI, Nations S, Herbelin L, et al. North America and South America (NA-SA) Neuropathy Project. International Journal of Neuroscience. 201310.3109/00207454.2013.782026

5. Laughlin RS, Dyck PJ, Melton LJ 3rd, Leibson C, Ransom J, Dyck PJ. Incidence and prevalence of CIDP and the association of diabetes mellitus. Neurology. 2009; 73(1):39-45. [PubMed: 19564582]

6. McCombe PA, Pollard JD, McLeod JG. Chronic inflammatory demyelinating polyradiculoneuropathy. A clinical and electrophysiological study of 92 cases. Brain. 1987; 110:1617-30. [PubMed: 3427403]

7. Holzbauer SM, DeVries AS, Sejvar JJ, et al. Epidemiologic investigation of immune-mediated polyradiculoneuropathy among abattoir workers exposed to porcine brain. PLoS One. 2010; 5(3):e9782. [PubMed: 20333310]

8. Dyck, PJ.; Arnason, BG. Chronic inflammatory demyelinating polyradiculoneuropathy. In: Dyck, PJ.; Thomas, PK.; Lambert, EH.; Bunge, R., editors. Peripheral neuropathy. 2. Philadelphia: WB Saunders; 1984. p. 2101-14.

9. Austin JH. Recurrent polyneuropathies and their corticosteroids treatment. Brain. 1958; 8:157-92. [PubMed: 13572689]

10. Viala K, Maisonobe T, Stojkovic T, Koutlidis R, Ayrignac X, Musset L, et al. A current view of the diagnosis, clinical variants, response to treatment and prognosis of chronic inflammatory demyelinating polyradiculoneuropathy. J Peripher Nerv Syst. 2010; 15(1):50-6. [PubMed: 20433605]

11. Gorson KC, Allam G, Ropper AH. Chronic inflammatory demyelinating polyneuropathy: clinical features and response to treatment in 67 consecutive patients with and without a monoclonal gammopathy. Neurology. 1997; 48:321-8. [PubMed: 9040714]

12. Sabatelli M, Madia F, Mignogna T, Lippi G, Quaranta L, Tonali P. Pure motor chronic inflammatory demyelinating polyneuropathy. J Neurol. 2001; 248:772-7. [PubMed: 11596782]

13. Dionne A, Nicolle MW, Hahn AF. Clinical and electrophysiological parameters distinguishing acute-onset chronic inflammatory demyelinating polyneuropathy from acute inflammatory demyelinating polyneuropathy. Muscle Nerve. 2010; 41(2):202-7. [PubMed: 19882646]

14. Ruts L, Drenthen J, Jacobs BC, van Doorn PA. Dutch GBS Study Group. Distinguishing acuteonset CIDP from fluctuating Guillain-Barre syndrome: a prospective study. Neurology. 2010; 74(21):1680-6. [PubMed: 20427754]

15. Hughes R, Sanders E, Hall S, Atkinson P, Colchester A, Payan P. Subacute idiopathic demyelinating polyradiculoneuropathy. Arch Neurol. 1992; 49:612-6. [PubMed: 1317700]

16. Oh SJ. Subacute demyelinating polyneuropathy responding to corticosteroid treatment. Arch Neurol. 1978; 35:509-16. [PubMed: 666609]

17. Oh SJ, Kurokawa K, de Almeida DF, Ryan HF, Claussen GC. Subacute inflammatory demyelinating polyneuropathy. Neurology. 2003; 61:1507-12. [PubMed: 14663033]

18. Saperstein DS, Katz JS, Amato AA, Barohn RJ. Clinical spectrum of chronic acquired demyelinating polyneuropathies. Muscle Nerve. 2001; 24:311-24. [PubMed: 11353415]

19. Koller H, Kieseier BC, Jander S, Hartung HP. Chronic inflammatory demyelinating polyneuropathy. N Engl J Med. 2005; 352:1343-56. [PubMed: 15800230]

20. Katz JS, Saperstein DS, Gronseth G, Amato AA, Barohn RJ. Distal acquired demyelinating symmetric (DADS) neuropathy. Neurology. 2000; 54:615-20. [PubMed: 10680792]

21. Saperstein DS, Amato AA, Wolfe GI, Katz JS, Nations SP, Jackson CE, et al. Multifocal acquired demyelinating sensory and motor neuropathy: the Lewis-Sumner syndrome. Muscle Nerve. 1999; 22:560-6. [PubMed: 10331353]

22. Viala K, Renié L, Maisonobe T, et al. Follow-up study and response to treatment in 23 patients with Lewis-Sumner syndrome. Brain. 2004; 127:2010-7. [PubMed: 15289267]

23. Verschueren A, Azulay JP, Attarian S, et al. Lewis-Sumner syndrome and multifocal motor neuropathy. Muscle Nerve. 2004; 31:88-94. [PubMed: 15536613]

24. Alaedini A, Sanders HW, Hays AP, Latov N. Antigangioside antibodies in multifocal acquired sensory and motor neuropathy. Arch Neurol. 2003; 60:42-6. [PubMed: 12533087]

25. Oh SJ, Claussen GC, Dae SK. Motor and sensory demyelinating mononeuropathy multiplex (multifocal motor and sensory demyelinating neuropathy): a separate variant of chronic 
inflammatory demyelinating polyneuropathy. J Peripher Nerv Syst. 1997; 2:362-9. [PubMed: 10975745]

26. Gorson KC, Ropper AH, Weinberg DH. Upper limb predominant, multifocal chronic inflammatory demyelinating polyneuropathy. Muscle Nerve. 1999; 22:758-65. [PubMed: 10366230]

27. Thomas PK, Claus D, Jaspert A, Workman JM, King RH, Larner AJ, et al. Focal upper limb demyelinating neuropathy. Brain. 1996; 119:765-74. [PubMed: 8673489]

28. Lewis RA, Sumner AJ, Brown MJ, Asbury AK. Multifocal demyelinating neuropathy with persistent conduction block. Neurology. 1982; 32:958-64. [PubMed: 7202168]

29. Gibbels E, Behse F, Kentenich M, Haupt WF. Chronic multifocal neuropathy with persistent conduction block (Lewis-Sumner syndrome). A clinicomorphologic study of two further cases with review of the literature. Clin Neuropathol. 1993; 12:343-52. [PubMed: 8287628]

30. Nukada H, Pollock M, Haas LF. Is ischemia implicated in chronic multifocal demyelinating neuropathy? Neurology. 1989; 39:106-10. [PubMed: 2909898]

31. Dyck PJ, Lais AC, Otha M, Bastron JA, Okasaki H, Groover RV. Chronic inflammatory polyradiculoneuropathy. Mayo Clin Proc. 1975; 50:621-37. [PubMed: 1186294]

32. Barohn RJ, Kissel JT, Warmolts JR, Mendell JR. Chronic inflammatory demyelinating polyradiculoneuropathy. Clinical characteristics, course, and recommendations for diagnostic criteria. Arch Neurol. 1989; 46:878-84. [PubMed: 2757528]

33. Dalakas M, Houff SA, Engel WK, Madden DL, Sever JL. CSF “monoclonal” bands in chronic relapsing polyneuropathy. Neurology. 1980; 30:864-7. [PubMed: 6251407]

34. Bromberg MB. Comparison of electrodiagnostic criteria for primary demyelination in chronic polyneuropathy. Muscle Nerve. 1991; 14:968-76. [PubMed: 1944409]

35. Thaisetthawatkul P, Logigian EL, Herrmann DN. Dispersion of the distal compound muscle action potential as a diagnostic criterion for chronic inflammatory demyelinating polyneuropathy. Neurology. 2002; 59(10):1526-32. [PubMed: 12451191]

36. Van den Bergh PY, Pieret F. Electrodiagnostic criteria for acute and chronic inflammatory demyelinating polyradiculoneuropathy. Muscle Nerve. 2004; 29(4):565-74. [PubMed: 15052622]

37. Dimachkie MM, Anderson HS, Gronseth GS, Herbelin L, Pasnoor M, McVey AL, et al. How common is sural nerve sparing in chronic inflammatory demyelinating polyneuropathy? 2008 meeting of the Inflammatory Neuropathy Consortium. JPNS. 2008; 13:166a.

38. Koski CL, Baumgarten M, Magder LS, Barohn RJ, Goldstein J, Graves M, et al. Derivation and validation of diagnostic criteria for chronic inflammatory demyelinating polyneuropathy. J Neurol Sci. 2009; 277(1-2):1-8. [PubMed: 19091330]

39••. Van den Bergh PY, Hadden RD, Bouche P, Cornblath DR, Hahn A, Illa I, et al. European Federation of Neurological Societies; Peripheral Nerve Society European Federation of Neurological Societies/Peripheral Nerve Society guideline on management of chronic inflammatory demyelinating polyradiculoneuropathy: report of a joint task force of the European Federation of Neurological Societies and the Peripheral Nerve Society - first revision. Eur J Neurol. 2010; 17(3):356-63. This report expands the electrophysiologic criteria and clinical phenotypes of CIDP. It also updates treatment recommendations. [PubMed: 20456730]

40. Rajabally YA, Samarasekera S. Electrophysiological sensory demyelination in typical chronic inflammatory demyelinating polyneuropathy. Eur J Neurol. 2010; 17(7):939-44. [PubMed: 20158514]

41. Molenaar DS, Vermeulen M, de Haan R. Diagnostic value of sural nerve biopsy in chronic inflammatory demyelinating polyneuropathy. J Neurol Neurosurg Psychiatry. 1998; 64:84-9. [PubMed: 9436733]

42. Bosboom WM, Van den Berg LH, Franssen H, et al. Diagnostic value of sural demyelination in chronic inflammatory demyelinating polyneuropathy. Brain. 2001; 124:2427-38. [PubMed: 11701597]

43. Sommer C, Koch S, Lammens M, Gabreels-Festen A, Stoll G, Toyka KV. Macrophage clustering as a diagnostic marker in sural nerve biopsies of patients with CIDP. Neurology. 2005; 65(12): 1924-9. [PubMed: 16380614]

44. England JD, Gronseth GS, Franklin G, Carter GT, Kinsella LJ, Cohen JA, et al. American Academy of Neurology. Practice Parameter: evaluation of distal symmetric polyneuropathy: role 
of autonomic testing, nerve biopsy, and skin biopsy (an evidence-based review). Report of the American Academy of Neurology, American Association of Neuromuscular and Electrodiagnostic Medicine, and American Academy of Physical Medicine and Rehabilitation. Neurology. 2009; 72(2):177-84. [PubMed: 19056667]

45. Hafer-Macko CE, Sheikh KA, Li CY, Ho TW, Cornblath DR, McKhann GM, et al. Immune attack on the Schwann cell surface in acute inflammatory demyelinating polyneuropathy. Ann Neurol. 1996; 39(5):625-35. [PubMed: 8619548]

46. Matsummuro K, Izumo S, Umehara F, Osame M. Chronic inflammatory demyelinating polyneuropathy: Histological and immunopathological studies in biopsied sural nerves. J Neurol Sci. 1994; 127:170-8. [PubMed: 7707076]

47. Kieseier BC, Tani M, Mahad D, Oka N, Ho T, Woodrofe N, et al. Chemokines and chemokine receptors in inflammatory demyelinating neuropathies: a central role for IP-10. Brain. 2002; 125:823-34. [PubMed: 11912115]

48. Leppert D, Hughes P, Huber S, Erne B, Grygar C, Said G, et al. Matrix metalloproteinase upregulation in chronic inflammatory demyelinating polyneuropathy and nonsystemic vasculitic neuropathy. Neurology. 1999; 53:62-70. [PubMed: 10408538]

49. Yan WX, Taylor J, Andrias-Kauba S, Pollard JD. Passive transfer of demyelination by serum or IgG from chronic inflammatory demyelinating polyneuropathy patients. Ann Neurol. 2000; 47:765-75. [PubMed: 10852542]

50. Koski CL, Sanders ME, Swoveland PT, et al. Activation of terminal components of complement in patients with Guillain-Barre syndrome and other demyelinating neuropathies. J Clin Invest. 1987; 80:1492-7. [PubMed: 3680509]

51. Hays AP, Lee SS, Latov N. Immune reactive C3d on the surface of myelin sheaths in neuropathy. J Neuroimmunol. 1988; 18:231-44. [PubMed: 2452830]

52. Allen D, Giannopoulos K, Gray I, Gregson N, Makowska A, Pritchard J, et al. Antibodies to peripheral nerve myelin proteins in chronic inflammatory demyelinating polyradiculoneuropathy. $\mathrm{J}$ Peripher Nerv Syst. 2005; 10(2):174-80. [PubMed: 15958128]

53. De Luca G, Lugaresi A, Iarlori C, et al. Prednisone and plasma exchange improve suppressor cell function in chronic inflammatory demyelinating polyneuropathy. J Neuroimmunol. 1999; 95:190 4. [PubMed: 10229130]

54. Chi LJ, Wang HB, Wang WZ. Impairment of circulating CD4+CD25+ regulatory T cells in patients with chronic inflammatory demyelinating polyradiculoneuropathy. J Peripher Nerv Syst. 2008; 13:54-63. [PubMed: 18346231]

55. Nimmerjahn F, Lünemann JD. Expression and function of the inhibitory Fc $\gamma$-receptor in CIDP. J Peripher Nerv Syst. 2011; 16 (Suppl 1):41-4. [PubMed: 21696497]

56. Tackenberg B, Jelcic I, Baerenwaldt A, Oertel WH, Sommer N, Nimmerjahn F, et al. Impaired inhibitory Fcgamma receptor IIB expression on B cells in chronic inflammatory demyelinating polyneuropathy. Proc Natl Acad Sci U S A. 2009; 106:4788-92. [PubMed: 19261857]

57. Comi C, Gaviani P, Leone M, Ferretti M, Castelli L, Mesturini R, et al. Fas-mediated T-cell apoptosis is impaired in patients with chronic inflammatory demyelinating polyneuropathy. $\mathrm{J}$ Peripher Nerv Syst. 2006; 11(1):53-60. [PubMed: 16519782]

58. Amato AA, Barohn RJ, Sahenk Z, Tushka PJ, Mendell JR. Polyneuropathy complicating bone marrow transplantation. Neurology. 1993; 43:1513-8. [PubMed: 8394521]

59. Rechthand E, Cornblath DR, Stern BJ, Meyerhoff JO. Chronic demyelinating polyneuropathy in systemic lupus erythematosus. Neurology. 1984; 34:1375-7. [PubMed: 6541313]

60. Romanick-Schmiedl S, Kiprov DD, Chalmers AC, Miller RG. Extraneural manifestations of chronic inflammatory demyelinating polyradiculoneuropathy. Am J Med. 1990; 89:531-4. [PubMed: 2220888]

61. Stewart JD, McKelvey R, Durcan L, Carpenter S, Karpati G. Chronic inflammatory demyelinating polyneuropathy (CIDP) in diabetics. J Neurol Sci. 1996; 142:59-64. [PubMed: 8902721]

62. Taylor BV, Wijdicks EFM, Poterucha JJ, Weinser RH. Chronic inflammatory demyelinating polyneuropathy complicating liver transplantation. Ann Neurol. 1995; 38:828-31. [PubMed: 7486876] 
63. Dyck PJ, Swanson CJ, Low PA, Bartleson JD, Lambert EH. Prednisone-responsive hereditary motor and sensory neuropathy. Mayo Clin Proc. 1982; 57:239-46. [PubMed: 7070119]

64. Mendell JR, Kolkin S, Kissel JT, Weiss KL, Chakeres DW, Rammohan KW. Evidence for central nervous system demyelination in chronic inflammatory demyelinating polyradiculoneuropathy. Neurology. 1987; 37(8):1291-4. [PubMed: 3614649]

65. Ad Hoc Subcommittee of the American Academy of Neurology. AIDS Task Force. Research criteria for diagnosis chronic inflammatory demyelinating polyneuropathy. Neurology. 1991; 41:617-8. [PubMed: 2027473]

66. Ginsberg L, Malik O, Kenton AR, Sharp D, Muddle JR, Davis MB, et al. Coexistent hereditary and inflammatory neuropathy. Brain. 2004; 127(Pt 1):193-202. [PubMed: 14607795]

67. Jann S, Bramerio MA, Facchetti D, Sterzi R. Intravenous immunoglobulin is effective in patients with diabetes and with chronic inflammatory demyelinating polyneuropathy: long term follow-up. J Neurol Neurosurg Psychiatry. 2009; 80(1):70-3. [PubMed: 18768571]

68. Kalita J, Misra UK, Yadav RK. A comparative study of chronic inflammatory demyelinating polyradiculoneuropathy with and without diabetes mellitus. Eur J Neurol. 2007; 14(6):638-43. [PubMed: 17539941]

69. Stübgen JP. Tumor necrosis factor-alpha antagonists and neuropathy. Muscle Nerve. 2008; 37(3): 281-92. [PubMed: 18041052]

70. Kundi S, Barohn R, McVey A, Dimachkie M, Pasnoor M, Herbelin L. Tacrolimus and RelapsingRemitting CIDP: a case report. J Clin Neuromuscul Dis. 2010; 11(3):9.

71. Wilson JR, Conwit RA, Eidelman BH, Starzl T, Abu-Elmagd K. Sensorimotor neuropathy resembling CIDP in patients receiving FK506. Muscle Nerve. 1994; 17(5):528-32. [PubMed: 7512691]

72. Echaniz-Laguna A, Battaglia F, Ellero B, Mohr M, Jaeck D. Chronic inflammatory demyelinating polyradiculoneuropathy in patients with liver transplantation. Muscle Nerve. 2004; 30(4):501-4. [PubMed: 15372442]

73. Labate A, Morelli M, Palamara G, Pirritano D, Quattrone A. Tacrolimus-induced polyneuropathy after heart transplantation. Clin Neuropharmacol. 2010; 33(3):161-2. [PubMed: 20502136]

74. Rotta FT, Sussman AT, Bradley WG, Ayyar DR, Sharma KR, Shebert RT. The spectrum of chronic inflammatory demyelinating polyneuropathy. J Neurol Sci. 2000; 173:129-39. [PubMed: 10675657]

75. Kelly JJ, Kyle RA, Miles JM, Dyck PJ. Osteosclerotic myeloma and peripheral neuropathy. Neurology. 1983; 33(2):202-10. [PubMed: 6296727]

76. Dispenzieri A, Kyle RA, Lacy MQ, Rajkumar SV, Therneau TM, Larson DR, et al. POEMS syndrome: definitions and long-term outcome. Blood. 2003; 101(7):2496-506. [PubMed: 12456500]

77. Watanabe O, Maruyama I, Arimura K, Kitajima I, Arimura H, Hanatani M, et al. Overproduction of vascular endothelial growth factor - Vascular permeability factor is causative in Crow-Fukase (POEMS) syndrome. Muscle Nerve. 1998; 21(11):1390-7. [PubMed: 9771661]

78. Watanabe O, Arimura K, Kitajima I, Osame M, Maruyama I. Greatly raised vascular endothelial growth factor (VEGF) in POEMS syndrome. Lancet. 1996; 347(9002):702. [PubMed: 8596427]

79. Dyck PJ, O'Brien PC, Oviatt KF, Dinapoli RP, Daube JR, Bartleson JD, et al. Prednisone improves chronic inflammatory demyelinating polyradiculoneuropathy more than no treatment. Ann Neurol. 1982; 11:136-41. [PubMed: 7041788]

80. Dyck PJ, Daube J, O’Brien P, Pineda A, Low PA, Windebank AJ, et al. Plasma exchange in chronic inflammatory demyelinating polyradiculoneuropathy. N Engl J Med. 1986; 314:461-5. [PubMed: 3511382]

81. Hahn AF, Bolton CF, Pillay N, Chalk C, Benstead T, Bril V, et al. Plasma-exchange therapy in chronic inflammatory demyelinating polyneuropathy: a double-blind, sham-controlled, cross-over study. Brain. 1996; 119:1055-66. [PubMed: 8813270]

82. Hahn AF, Bolton CF, Zochodne D, Feasby TE. Intravenous immunoglobulin treatment in chronic inflammatory demyelinating polyneuropathy: a double-blind, placebo-controlled, cross-over study. Brain. 1996; 119:1067-77. [PubMed: 8813271] 
83. Mendell JR, Barohn RJ, Freimer ML, Kissel JT, King W, Nagaraja HN, et al. Working group on peripheral neuropathy: randomized controlled trial of IVIg in untreated chronic inflammatory demyelinating polyradiculoneuropathy. Neurology. 2001; 56:445-9. [PubMed: 11222785]

84. Hughes RA, Donofrio P, Bril V, Dalakas MC, Deng C, Hanna K, et al. ICE Study Group. Intravenous immune globulin (10\% caprylate-chromatography purified) for the treatment of chronic inflammatory demyelinating polyradiculoneuropathy (ICE study): a randomized placebocontrolled trial. Lancet Neurol. 2008; 7(2):136-44. [PubMed: 18178525]

85. Hughes R, Bensa S, Willison H, et al. Randomized controlled trial of intravenous immunoglobulin versus oral prednisolone in chronic inflammatory demyelinating polyradiculoneuropathy. Ann Neurol. 2001; 50:195-201. [PubMed: 11506402]

86. Lopate G, Pestronk A, Al-Lozi M. Treatment of chronic inflammatory demyelinating polyneuropathy with high-dose intermittent intravenous methylprednisolone. Arch Neurol. 2005; 62:249-54. [PubMed: 15710853]

87. Muley SA, Kelkar P, Parry GJ. Treatment of chronic inflammatory demyelinating polyneuropathy with pulsed oral steroids. Arch Neurol. 2008; 65(11):1460-4. [PubMed: 19001164]

88. Harbo T, Andersen H, Jakobsen J. Acute motor response following a single IVIG treatment course in chronic inflammatory demyelinating polyneuropathy. Muscle Nerve. 2009; 39(4):439-47. [PubMed: 19229876]

89. Bril V, Banach M, Dalakas MC, Deng C, Donofrio P, Hanna K, et al. ICE Study Group. Electrophysiologic correlations with clinical outcomes in CIDP. Muscle Nerve. 2010; 42(4):4927. [PubMed: 20665514]

90. Lee DH, Linker RA, Paulus W, Schneider-Gold C, Chan A, Gold R. Subcutaneous immunoglobulin infusion: a new therapeutic option in chronic inflammatory demyelinating polyneuropathy. Muscle Nerve. 2008; 37(3):406-9. [PubMed: 17918749]

91. Kaneko Y, Nimmerjahn F, Ravetch JV. Anti-inflammatory activity of immunoglobulin G resulting from Fc sialylation. Science. 2006; 313(5787):670-3. [PubMed: 16888140]

92. Dyck PJ, O’Brien PC, Swanson C, et al. Combined azathioprine and prednisone in chronic inflammatory-demyelinating polyneuropathy. Neurology. 1985; 35:1173-6. [PubMed: 4022350]

93. Hodgkinson SJ, Pollard JD, McLeod JG. Cyclosporine A in the treatment of chronic demyelinating polyradiculopathy. J Neurol Neurosurg Psychiatry. 1990; 53:327-30. [PubMed: 2341846]

94. Barnett MH, Pollard JD, Davies L, McLeod JG. Cyclosporin A in resistant chronic inflammatory demyelinating polyradiculoneuropathy. Muscle Nerve. 1998; 21(4):454-60. [PubMed: 9533779]

95. Koski CL. Guillain-Barre syndrome and chronic inflammatory demyelinating polyneuropathy: pathogenesis and treatment. Semin Neurol. 1994; 14:123-30. [PubMed: 7984827]

96. Good JL, Chehrenama M, Mayer RF, Koski CL. Pulsed cyclophosphamide in chronic inflammatory demyelinating polyneuropathy. Neurology. 1998; 51:1735-8. [PubMed: 9855536]

97. Brannagan TH, Pradham A, Heiman-Patterson T, et al. High-dose cyclophosphamide without stem-cell rescue for refractory CIDP. Neurology. 2002; 58:1856-8. [PubMed: 12084892]

98. Chaudhry V, Cornblath DR, Griffin JW, O’Brien R, Drachman DB. Mycophenolate mofetil: a safe and promising immunosuppressant in neuromuscular diseases. Neurology. 2001; 56:94-6. [PubMed: 11148242]

99. Mowzoon N, Sussman A, Bradley WG. Mycophenolate (CellCept) treatment of myasthenia gravis, chronic inflammatory polyneuropathy, and inclusion body myositis. J Neurol Sci. 2001; 185(2): 119-22. [PubMed: 11311292]

100. Gorson KC, Amato AA, Ropper AH. Efficacy of mycophenolate mofetil in patients with chronic immune demyelinating polyneuropathy. Neurology. 2004; 63:715-7. [PubMed: 15326250]

101. Sabatelli M, Mignona T, Lippi G, Milone M, Lazzaro VD, Tonali P. Interferon-alpha may benefit steroid unresponsive chronic inflammatory demyelinating polyneuropathy. J Neurol Neurosurg Psychiatry. 1995; 58:638-9. [PubMed: 7745420]

102. Choudhary PP, Thompson N, Hughes RAC. Improvement following interferon beta in chronic inflammatory demyelinating polyradiculoneuropathy. J Neurol. 1995; 242:252-3. [PubMed: 7798127] 
103. Gorson KC, Ropper AH, Clark BD, Dew RB, Simovic D, Allam G. Treatment of chronic inflammatory demyelinating polyneuropathy with interferon alpha 2a. Neurology. 1998; 50:84-7. [PubMed: 9443462]

104. Hadden RDM, Sharrack B, Bensa S, Soudain SE, Hughes RAC. Randomized trial of interferon B-1a in chronic inflammatory demyelinating polyradiculoneuropathy. Neurology. 1999; 53:5761. [PubMed: 10408537]

105. Kuntzer T, Radziwill AJ, Lettry-Trouillat R, et al. Interferon-B1a in chronic inflammatory demyelinating polyneuropathy. Neurology. 1999; 53:1364-5. [PubMed: 10522905]

106. Pavesi G, Cattaneo L, Marbini A, Gemignani F, Mancia D. Long-term efficacy of interferonalpha in chronic inflammatory demyelinating neuropathy. J Neurol. 2002; 249:777-9. [PubMed: 12173577]

107. Vallat JM, Hahn AF, Leger JM, et al. Interferon beta 1a as an investigational treatment for CIDP. Neurology. 2003; 60 (Suppl 3):S23-8. [PubMed: 12707419]

108. Fialho D, Chan YC, Allen DC, Reilly MM, Hughes RA. Treatment of chronic inflammatory demyelinating polyradiculoneuropathy with methotrexate. J Neurol Neurosurg Psychiatry. 2006; 77:544-7. [PubMed: 16543541]

109. RMC Trial Group. Randomized controlled trial of methotrexate for chronic inflammatory demyelinating polyradiculoneuropathy (RMC trial): a pilot, multi-center study. Lancet Neurol. 2009; 8(2):158-64. [PubMed: 19136303]

110. Hughes RA, Gorson KC, Cros D, Griffin J, Pollard J, Vallat JM, et al. Avonex CIDP Study Group. Intramuscular interferon beta-1a in chronic inflammatory demyelinating polyradiculoneuropathy. Neurology. 2010; 74(8):651-7. [PubMed: 20177118]

111. Niermeijer JM, Eurelings M, Lokhorst H, Franssen H, Fijnheer R, Wokke JH, et al. Neurologic and hematologic response to fludarabine treatment in IgM MGUS polyneuropathy. Neurology. 2006; 67(11):2076-9. [PubMed: 17159126]

112. Gladstone DE, Prestrud AA, Brannagan TH III. High-dose cyclophosphamide results in long-term disease remission with restoration of a normal quality of life in patients with severe refractory chronic inflammatory demyelinating polyneuropathy. J Peripher Nerv Syst. 2005; 10(1):11-6. [PubMed: 15703014]

113. Benedetti L, Briani C, Franciotta D, Fazio R, Paolasso I, Comi C, et al. Rituximab in patients with chronic inflammatory demyelinating polyradiculoneuropathy: a report of 13 cases and review of the literature. J Neurol Neurosurg Psychiatry. 2011; 82(3):306-8. [PubMed: 20639381]

114. Marsh EA, Hirst CL, Llewelyn JG, Cossburn MD, Reilly MM, Krishnan A, et al. Alemtuzumab in the treatment of IVIG-dependent chronic inflammatory demyelinating polyneuropathy. $\mathrm{J}$ Neurol. 2010; 257(6):913-9. [PubMed: 20049473]

115. Gordon, PH.; Brannagan, TH.; Latov, N. Neurological manifestations of paraproteinemia and cryoglobulinemia. In: Aminoff, MJ.; Goetz, CG., editors. Handbook of clinical neurology. Science. Elsevier; 1998. p. 431-59.

116. Oyama RMD, Sufit MDY, Loh MDL, Statkute MDK, Yaung RNK, Quigley RNE, et al. Nonmyeloablative autologous hematopoietic stem cell transplantation for refractory CIDPY. Neurology. 2007; 69:1802-3. [PubMed: 17967996]

117. Kuwabara S, Misawa S, Kanai K, Kikkawa Y, Nishimura M, Nakaseko C, et al. Autologous peripheral blood stem cell transplantation for POEMS syndrome. Neurology. 2006; 66(1):105-7. [PubMed: 16401856]

118. Mahdi-Rogers M, Kazmi M, Ferner R, Hughes RA, Renaud S, Steck AJ, et al. Autologous peripheral blood stem cell transplantation for chronic acquired demyelinating neuropathy. $\mathrm{J}$ Peripher Nerv Syst. 2009; 14(2):118-24. [PubMed: 19691534]

119. Kuwabara S, Misawa S, Kanai K, Sawai S, Hattori T, Nishimura M, et al. Thalidomide reduces serum VEGF levels and improves peripheral neuropathy in POEMS syndrome. J Neurol Neurosurg Psychiatry. 2008; 79(11):1255-7. [PubMed: 18469028]

120. Hughes RA, Bouche P, Cornblath DR, Evers E, Hadden RD, Hahn A, et al. In: European Federation of Neurological Societies/Peripheral Nerve Society guideline on management of chronic inflammatory demyelinating polyradiculoneuropathy: report of a joint task force of the 
European Federation of Neurological Societies and the Peripheral Nerve Society. Eur J Neurol. 2006; 13(4):326-32. [PubMed: 16643309]

121. Bouchard C, Lacroix C, Plante V, Adams D, Chedru F, Guglielmi JM, et al. Clinicopathologic findings and prognosis of chronic inflammatory demyelinating polyneuropathy. Neurology. 1999; 52:498-503. [PubMed: 10025777] 
Table 1

Comparison of the chronic acquired immune-mediated demyelinating polyneuropathies

\begin{tabular}{|c|c|c|c|c|}
\hline & CIDP & DADS neuropathy & MADSAM neuropathy & MMN \\
\hline \multicolumn{5}{|l|}{ Clinical features } \\
\hline Weakness & $\begin{array}{l}\text { Symmetric; } \\
\text { proximal + distal }\end{array}$ & $\begin{array}{l}\text { Symmetric; distal } \\
\text { only; mild or no } \\
\text { weakness }\end{array}$ & $\begin{array}{l}\text { Asymmetric; distal > proximal; } \\
\text { upper limbs > lower limbs }\end{array}$ & $\begin{array}{l}\text { Asymmetric; distal > } \\
\text { proximal; upper limbs > } \\
\text { lower limbs }\end{array}$ \\
\hline Sensory deficits & Yes; symmetric & Yes; Symmetric & $\begin{array}{l}\text { Yes; multifocal (distribution of } \\
\text { individual nerves) }\end{array}$ & No \\
\hline Reflexes & $\begin{array}{l}\text { Reduced or absent } \\
\text { symmetrically }\end{array}$ & $\begin{array}{l}\text { Reduced or absent } \\
\text { symmetrically }\end{array}$ & $\begin{array}{l}\text { Reduced or absent (multifocal or } \\
\text { diffuse) }\end{array}$ & $\begin{array}{l}\text { Reduced or absent } \\
\text { (multifocal or diffuse) }\end{array}$ \\
\hline \multicolumn{5}{|l|}{ Electrophysiology } \\
\hline \multicolumn{5}{|l|}{ Abnormal CMAPs: } \\
\hline Demyelinating features & Usually symmetric & $\begin{array}{l}\text { Usually symmetric } \\
\text { Prolonged distal } \\
\text { latencies }\end{array}$ & Asymmetric (multifocal) & Asymmetric (multifocal) \\
\hline Conduction block & Frequent & Uncommon & Frequent & Frequent \\
\hline Abnormal SNAPs & Usually symmetric & Usually symmetric & Asymmetric (multifocal) & SNAPs are normal \\
\hline \multicolumn{5}{|l|}{ Laboratory findings } \\
\hline CSF Protein & Usually elevated & Usually elevated & Usually elevated & Usually normal \\
\hline Monoclonal protein & $\begin{array}{l}\text { Occasionally } \\
\text { present; Usually } \\
\text { IgG or IgA }\end{array}$ & $\begin{array}{l}\text { IgM- } \kappa \text { present in } \\
\text { the majority; } 50 \\
\%-70 \% \text { are MAG } \\
\text { positive }\end{array}$ & Rarely present & Rarely present \\
\hline Anti-GM1 Antibodies & Rarely present & Not present & Rarely present & Frequently present (50\%) \\
\hline \multicolumn{5}{|l|}{ Sensory nerve biopsy: } \\
\hline Demyelination/remyelination & Frequent & Frequent & Frequent; Sometimes asymmetrical & Occasional; Minimal findings \\
\hline \multicolumn{5}{|l|}{ Treatment response } \\
\hline Prednisone & Yes & Poor $^{a}$ & Yes & No \\
\hline Plasma exchange & Yes & Poor $^{a}$ & Possible (more study needed) & No \\
\hline IVIg & Yes & Poor $^{a}$ & Yes & Yes \\
\hline Cyclophosphamide & Yes & Poor $^{a}$ & Possible (more study needed) & Yes \\
\hline
\end{tabular}

$C I D P$ chronic inflammatory demyelinating polyneuropathy, CMAPs compound motor action potentials, CSF cerebrospinal fluid, DADS distal acquired demyelinating symmetrical, IVIg intravenous immunoglobulin, MADSAM multifocal acquired demyelinating sensory and motor, MAG myelin associated glycoprotein, $M M N$ multifocal motor neuropathy, SNAPs sensory nerve action potentials.

${ }^{a}$ When associated with an IgM-MGUS.

Treatment responses in DADS neuropathy patients without a MGUS are more similar to those with CIDP. 
